\title{
A IMPORTÂNCIA DA RODA DE CONVERSA NA EDUCAÇÃO INFANTIL
}

\author{
Dasny Pestana de Pinto ${ }^{1}$ \\ Eliana Maria de Souza Cruz ${ }^{2}$ \\ Joilce Amorim Pinto ${ }^{3}$ \\ Terezinha Silveira Braga ${ }^{4}$ \\ Vanildes Célia de Paula ${ }^{5}$
}

RESUMO: As rodas de conversa são atividades de linguagem realizadas de modo permanente na Educação Infantil, com o intuito de desenvolver a oralidade, a expressão e a interação da criança. A roda de conversa é um método bastante utilizado, mas geralmente não é visto como uma prática pedagógica. Apesar disso, o seu objetivo é a construção de um espaço de diálogo que permita aos alunos se expressarem e aprenderem em conjunto. Para criar uma roda de conversa, o professor deve fazer um planejamento do conteúdo com um objetivo claro, estabelecer as regras e intervir quando necessário para garantir a compreensão dos alunos. Além disso, é necessário organizar um espaço adequado em que todos estejam confortáveis e possam se ver, assim como também escolher assuntos que possam ser desenvolvidos pela turma e trazer dados que possam auxiliar. É papel do professor dar voz ao que os alunos têm a dizer e deixar que todos participem, permitindo que eles digam o que pensam e o que sabem sobre o conteúdo.

Palavras-chave: Roda de conversa. Educação Infantil. Linguagem.

ABSTRACT: Conversation circles are language activities carried out permanently in Kindergarten, with the aim of developing the child's orality, expression and interaction. The conversation wheel is a widely used method, but it is not generally seen as a pedagogical practice. Despite this, its objective is to build a space for dialogue that allows students to express themselves and learn together. To create a conversation circle, the teacher must plan the content with a clear objective, establish the rules and intervene when necessary to ensure student understanding. In addition, it is necessary to organize an adequate space where everyone is comfortable and can see each other, as well as choosing subjects that can be developed by the class and bringing data that can help. It is

\footnotetext{
${ }^{1}$ Graduada em Pedagogia - Docência para a Educação Infantil e Anos Iniciais do Ensino Fundamental e na Empresa pelo UNIVAG - Centro Universitário, Especialista em Educação Infantil pela Faculdade Mantenense dos Vales Gerais - INTERVALE.

${ }^{2}$ Graduada em Pedagogia pela FAEL - Faculdade Educacional da Lapa, Especialista em Educação Infantil pela Faculdades Integradas de Várzea Grande - FIAVEC.

3 Graduada em Pedagogia pela FAEL - Faculdade Educacional da Lapa, Especialista em Educação Infantil pela Faculdades Integradas de Várzea Grande - FIAVEC.

${ }_{4}^{4}$ Graduada em Pedagogia pela Faculdades Integradas Urubupungá, Especialista em Metodologia do Ensino pela Faculdade de Educação Fátima do Sul.

5 Graduada em Pedagogia pela Faculdade Mantenense dos Vales Gerais - INTERVALE, Especialista em Educação Infantil e as Séries Iniciais do Ensino Fundamental pela Faculdade Integrada de Ariquemes.
} 
the teacher's role to voice what students have to say and let everyone participate, allowing them to say what they think and what they know about the content.

Keywords: Conversation Wheel. Child education. Learning.

\section{INTRODUÇÃO}

A rotina em atividades na roda de conversa deve ser valorizada e colocada em prática no processo de desenvolvimento escolar da criança. Como diz Vasconcelos (1997, p. 44): “[...] Mais do que estudar um cenário, eu estava a aprender com ele [...]”.

Através da roda de conversa na Educação Infantil, pode ser tratado assuntos diferenciados com o objetivo de explorar idéias, interagir, educar e aprender. A aprendizagem acontece de diferentes maneiras e quanto mais possibilidades são exploradas, melhor. Para envolver todos os alunos e desenvolver mais autonomia e coletividade, a roda de conversa é uma ótima metodologia que pode ser aplicada em todas as salas de aula.

Percebe-se que este instrumento utilizado nas escolas proporciona diálogo das crianças entre elas e também com os professores nos quais todos podem se olhar e aprender

uns com os outros. Percebe-se que um dos principais motivos para realização das rodas de conversa é o aprendizado do diálogo entre todos, sabendo respeitar o outro, realizar acordos e combinados, fazer com que as trocas de idéias contribuam para o desenvolvimento social das crianças, beneficiando assim, a qualidade das relações entre as crianças e na qual consigam expor seus sentimentos, vontades e pensamentos por meio da conversa.

É indispensável que as crianças tenham um momento de liberdade para conversar e que desta maneira tenham a certeza que são ouvidas e que merecem atenção, por isso, é muito importante que os professores vejam seus alunos como um ser humano de pouca idade, que também tem suas opiniões próprias. Por meio da roda de conversa temos a oportunidade de conhecer melhor os nossos alunos, sendo assim, ensinamos e aprendemos juntos, conhecendo as diferenças e semelhanças existentes na turma.

O presente artigo tem por objetivo a investigação da importância da roda de conversa na Educação Infantil, no qual foi realizado um estudo bibliográfico sobre o tema como ponto de partida. Este artigo é de suma importância, pois nota-se que a roda de conversa está presente diariamente na Educação Infantil 


\section{DESENVOLVIMENTO}

\section{I Roda de conversa}

A roda de conversa é uma prática fundamental para aumentar a competência comunicativa de cada criança. As mesmas são colocadas em círculo com o objetivo de dialogar sobre um determinado tema exposto pelo professor, realizando a comunicação com as outras crianças, onde elas interagem entre si, desenvolvendo a autonomia, expressando seus pensamentos livremente, vivenciando confronto de idéias. A roda de conversa contribui para que as crianças construam conhecimentos importantes para o seu desenvolvimento, para que elas sejam capazes de observar, perguntar e imaginar e explorar suas idéias. (SILVA, 2016).

A roda de conversa tem sido compreendida, no contexto escolar, como um espaço de exercício democrático, que privilegia o estabelecimento de diálogos, debates e troca de idéias. Na Educação Infantil, essa atividade constitui-se como elemento frequente da organização didática e metodológica, como forma de subsidiar um trabalho com a linguagem oral e valorizar a produção infantil. A roda de conversa é instrumento regularmente utilizado no cotidiano da Educação Infantil para o trabalho com os conteúdos escolares, mas, também, é um método de pesquisa que permite ao sujeito expressar sua singularidade (SILVA, 2016).

Para Moura \& Lima (2014) a roda de conversa, constitui-se, no âmbito da pesquisa narrativa, um mecanismo que possibilita a partilha de experiências e o desenvolvimento de reflexões sobre diversas temáticas, em um processo mediado pela interação com os pares, por meio de diálogos internos e no silêncio observador e reflexivo.

Moura \& Lima (2014) identificam a roda de conversa como instrumento de investigação de natureza qualitativa, uma abordagem legítima de busca do conhecimento científico. Através da roda, é possível explorar os significados criados pelos sujeitos e pelos grupos sociais em relação a um problema social. 
Segundo Moura \& Lima (2014) o sujeito é sempre um narrador em potencial. O fato é que ele não narra sozinho, mas reproduz vozes, discursos e memórias de outras pessoas, que se associam à sua no processo de rememoração e de socialização, e o discurso narrativo, no caso da roda de conversa, é uma construção coletiva.

No contexto da produção de dados, o pesquisador deve compreender que as memórias culturais e individuais estão intimamente ligadas. Para Moura \& Lima (2014) a roda de conversa constitui-se como um mecanismo de produção de dados da pesquisa narrativa, em que é possível haver uma reflexão coletiva, na medida em que se criam espaços de diálogo e debate.

$\mathrm{Na}$ Educação Infantil, a roda de conversa torna-se reconhecida como importante instrumento democrático que propicia a interação entre os sujeitos, que se constituem pela linguagem. O Referencial Curricular Nacional para Educação Infantil (RCNEI, 1998) concebe-a como: [...] momento privilegiado de diálogo e intercâmbio de idéias. Através desse exercício cotidiano as crianças podem ampliar suas capacidades comunicativas, como a fluência para falar, perguntar, expor idéias, dúvidas e descobertas, ampliar seu vocabulário e aprender a valorizar o grupo como instância de troca e aprendizagem. A participação na roda permite que as crianças aprendam a olhar e a ouvir os amigos, trocando experiências.

Pode-se, na roda, contar fatos às crianças, descrever ações "[...] ler e contar histórias, cantar, declamar poesias, dizer parlendas, etc.” (BRASIL, 1998, p. 138). Apesar de a roda de conversa apresentar-se como um instrumento democrático, que permite o movimento das vozes infantis, surgem certas problemáticas a respeito dos critérios para avaliarmos a natureza democrática dessa prática e, também, das contribuições da roda de conversa para um trabalho com a linguagem verbal na Educação Infantil, enquanto espaço de humanização da criança, e do papel do professor frente a essa prática. Muitas dessas questões nos levaram a eleger esse objeto de pesquisa, e iniciamos com uma investigação sobre a "Roda" na Educação Infantil.

Esse exercício reflexivo se torna indispensável para que se possa realizar uma análise criteriosa, desviando de suposições. Por isso, é necessário buscar em pesquisas existentes nessa área, quais as contribuições e limitações que apontam acerca da roda de conversa para a educação da criança nas primeiras etapas da escolarização. 


\subsection{A importância da roda de conversa para as crianças}

No Referencial Curricular Nacional para a Educação Infantil (RCNEI, 1998), a roda de conversa é vista como um momento de diálogo e troca de ideias, onde a mesma se dá por troca de falas, aprendizagem, dúvidas e descobertas, é importante ressaltar também que a roda serve para valorizar o grupo.

Esse instrumento pedagógico chamado, roda de conversa contribuir para a construção do conhecimento, valoriza a relação dialógica entre os diferentes sujeitos, fazendo assim uma construção coletiva de saberes, respeitando as diferenças de cada um.

Este momento é de suma importância para o desenvolvimento da fala e da escuta, bem como do respeito para com o outro, pois é preciso respeitar as diferenças e o ponto de vista do outro. Neste ponto também se constrói e reconstrói novos conhecimentos entre os envolvidos na roda de conversa.

É importante ressaltar que esses momentos em que a criança participa na troca de diálogos revestem-se de uma identidade de grupo que ao mesmo tempo revela sua própria identidade histórica, proporcionando assim uma responsabilidade individual e coletiva, estabelecendo novos significados a sua vivência e a tomada de decisões.

Esse momento de escuta na roda de conversa estimula a criança a reconhecer o outro, e suas ideias e formas de pensar, segundo Warschauer (1993, p. 46) as rodas se caracterizam por reunir indivíduos com histórias de vida diferentes e maneiras próprias de pensar e sentir, de modo que os diálogos, não obedecem a uma mesma lógica. São às vezes atravessados pelos diferentes significados que um tema desperta em cada participante.

Esses diálogos são muito relevantes, pois é a partir deles que as crianças organizam suas ideias, podendo expressá-las e problematizá-las, e até mesmo transformar sua opinião, criação de novas ideias e reflexão sobre diferentes temas trazidos na roda.

Durante este momento as crianças têm a liberdade de expressão, podem sanar suas dúvidas e curiosidades, compartilhar saberes, experiências, tristezas e alegrias, em um processo de diálogo e aprendizagem que envolve a fala e escuta do outro.

A roda de conversa é um momento de interação e diálogo, o qual tem por objetivo a troca de saberes sobre determinada temática, e a reconstrução do conhecimento, momento que a criança pode se expressar e dar a sua opinião, desta forma Freire \& Shor 
(1987) afirmam: O diálogo não é uma situação na qual podemos fazer tudo o que queremos. Isto é, ele tem limites e contradições que condicionam o que podemos fazer. Para alcançar os objetivos de transformação, o diálogo implica em responsabilidade, direcionamento, determinação, disciplina, objetivos (FREIRE \& SHOR, 1987).

A roda de conversa precisa ter um direcionamento sobre o que vai ser conversado, ou seja, uma pauta que deixe claro o assunto e o objetivo da roda bem como os combinados para que todos tenham direito a participar e expressar seus pensamentos e opiniões sobre determinado assunto, provocando muitas vezes até um conflito de ideias, mas um conflito que pode ser construtivo no qual há troca de saberes entre os participantes da roda.

A roda de conversa é, portanto, muito importante no dia a dia da educação infantil, pois é um momento de partilha, aprendizagens, em que a criança aprende a conversar, pois a roda é para conversar e não apenas para ocupar tempo como afirmou Bombassaro (2010). Desta forma o professor deve explorar esse momento, buscando trazer temáticas em que envolvam o grupo todo, para que haja uma participação ativa na roda.

Desta forma mesmo que a roda seja realizada todos os dias, é de suma importância o professor realizar o planejamento delas, como planeja as suas aulas, para que assim não seja uma coisa mecânica, mas mobilizadora para qual devemos buscar identificar e trazer assuntos que dizem respeito ao grupo e que realmente seja relevante se trabalhar. Ou seja, a roda vem com o intuito de auxiliar o professor a abordar diferentes assuntos fazendo com que as crianças contribuam de diferentes maneiras, onde é possível então a troca de saberes, mas para isso a Roda deve ser planejada, tanto o assunto a ser trabalhado quanto a sua duração.

Durante o debate elas têm a liberdade de falar seus pensamentos e ouvir diferentes pontos de vistas dos colegas, aprendendo assim a respeitar uma opinião diferente, vale ressaltar que: “[...] quanto mais às crianças puderem falar em situações diferentes, como contar o que lhes aconteceu em casa, contar histórias, dar um recado, explicar um jogo ou pedir uma informação, mais poderá desenvolver suas capacidades comunicativas de maneira significativa [...]” (RCNEI, 1998, p. 121).

O Referencial Curricular Nacional para a Educação Infantil (RCNEI, I998) afirma que a aprendizagem oral permite comunicar ideias, pensamentos e intenções de diversas naturezas, influenciar o outro e constituir relações interpessoais. O aprendizado 
ocorre inserido dentro de um contexto. Assim quanto mais as crianças falam em ocasiões diferentes, mais desenvolvem suas capacidades comunicativas de modo significativo.

É necessário levar em consideração que a linguagem oral é o principal instrumento de comunicação. É importante o reconhecimento de que a fala é básica na vida e de suma importância para o ser humano. De acordo com Araújo (I965, p. II) apud Chaer \& Guimarães, (2012, p. 72): “o homem está na permanente dependência dos símbolos verbais e, por esse motivo, o desenvolvimento da linguagem é elemento essencial à sua perfeita realização na sociedade em que vive”.

Portanto é através da roda de conversa que as crianças também ampliam sua oralidade, nas brincadeiras e interação com o professor.

A roda de conversa é um momento enriquecedor e significativo com as crianças do primeiro ano do ensino fundamental, vale ressaltar que: “[...] a capacidade de desenvolvimento de linguagem nas crianças é marcada pelas possibilidades de trocas verbais e discursivas e o adulto ou o professor tem uma função importante nesse processo no âmbito escolar, podendo promover uma série de atividades para essa evolução [...]" (RONCATO \& LACERDA. 2005).

Chaer \& Guimaraes (2012, p. 72) dizem que: “[...] A linguagem oral é um dos aspectos fundamentais de nossa vida, pois é por meio dela que nos socializamos, construímos conhecimentos, organizamos nossos pensamentos e experiências, ingressamos no mundo. Assim, ela amplia as inserções e de participação nas diversas práticas sociais $[\ldots] ”$.

\subsection{O papel do professor na roda de conversa}

O professor é muito importante na prática durante a realização de uma roda de conversa, pois é ele quem define os meios e possibilidade para fazer as crianças falarem mais, promovendo o desenvolvimento da capacidade de comunicação, propondo brincadeiras, lendo e contando histórias, expondo idéias para debates, utilizando símbolos e desenhos, estimulando a criatividade, auxiliando a criança que possui dificuldade a expor suas ideias, aprendendo com elas, valorizando cada opinião, é por meio dessa prática em sala de aula o professor consegue ter melhor relacionamento e comportamento com o 
aluno, e dando continuidade ao assunto. De acordo com Junqueira Filho (2005, p. 54): “[...] Professores e alunos são muito dupla forte, um par dinâmico que pode muito na vida de cada um deles [...]”.

Através da roda de conversa os alunos podem debater assuntos crítico definido pelo instrutor o qual deve levar em conta o interesse e a capacidade de concentração dos alunos e até mesmo aprender boas maneiras de como se comportar uns com os outros.

Por isso se torna importante utilizar meios para instigar a curiosidade das crianças para a roda de conversa, como por exemplo: propor brincadeiras para a organização da roda, utilizar fantoches, músicas, brinquedos, etc. Dentre os diversos aspectos sublinhados pelo autor, ressaltar que: "Discute-se a maneira como o professor encaminha/coordena/posiciona as diferentes enunciações dos alunos no fazer/produzirem conhecimento em classe. Isto é, a maneira como ele compreende e lida com a tessitura discursiva produzida pelas/nas suas ações e pelas/nas ações dos alunos em sala de aula pode gerar espaços de construção conjunta, permitindo aos participantes uma aprendizagem crítica que leve ao desenvolvimento [...]” (VYGOTSKY, 1994).

Segundo Bombassaro (2010) o planejamento da roda começa antes mesmo do professor ir ao encontro das crianças e convocá-las para a roda; mas começa quando o professor planeja a roda, retomando suas memórias e seus registros sobre as rodas anteriores, pensando-a na relação com as demais situações que vão compor a rotina do dia.

Desta forma mesmo que a roda seja realizada todos os dias, é de suma importância o professor realizar o planejamento delas, como planeja as suas aulas, para que assim não seja uma coisa mecânica, mas mobilizadora para qual devemos buscar identificar e trazer assuntos que dizem respeito ao grupo e que realmente seja relevante se trabalhar.

A roda vem com o intuito de auxiliar o professor a abordar diferentes assuntos fazendo com que as crianças contribuam de diferentes maneiras, onde é possível então a troca de saberes, mas para isso a roda deve ser planejada, tanto o assunto a ser trabalhado quanto a sua duração.

Para Bombassaro (2010) a roda é muito importante, porém, ainda tem professores que por esse momento ser de liberdade de expressão das crianças, esclarecimento das atividades do dia não percebem a riqueza de oportunidades de 
conhecimento e desenvolvimento, que este momento oferece, e usam a roda simplesmente para preencher a rotina.

O momento da roda de conversa se destina a investigação, a busca de saberes acerca de determinado assunto, fazendo assim, com que as crianças sejam capazes de construir diferentes conhecimentos importantes para o seu desenvolvimento, estimulandoas para que aprendam a observar, perguntar, pensar, imaginar, dentre outras possibilidades (BOMBASSARO, 2010).

O momento da roda é importante, pois proporciona situações de aprendizagem, estamos oportunizando aos participantes, que aprendam cada vez mais de uma forma mais lúdica e atraente, é através da conversa que as crianças aprendem a conversar, a respeitar o outro, pois de acordo com Warschauer (1993) a característica da roda é reunir indivíduos com histórias de vida diferentes e maneiras próprias de pensar e sentir, de modo que os diálogos nascidos desse encontro, não obedecem a uma mesma lógica. São, às vezes, atravessados pelos diferentes significados que um tema desperta em cada participante. A constância dos encontros propicia um maior entrelaçamento dos significados individuais, a interação aumenta e criam-se significados comuns, às vezes até de uma linguagem própria.

Warschauer (1993) nos faz perceber que a roda de conversa assim como em qualquer relação tem conflitos e desentendimentos, pois somos diferentes e pensamos diferente uns dos outros, e o diálogo se faz necessário, para a resolução dos conflitos. Notase então como a roda de conversa auxilia nesse meio, pois ela consegue fazer uma aproximação entre os membros do grupo/turma, melhorando até mesmo a relação entre eles. Tendo em vista que uma das finalidades da roda de conversa é o desenvolvimento da comunicação, desta forma, ela se torna indispensável na rotina das crianças, pois é por meio da conversa que a criança aprende diferentes competências. Pois é nesta fase que a criança se encontra em uma educação que é baseada na identidade e autonomia, sendo que elas aprendem por meio da observação direta e pela exploração pessoal, e muitas vezes também pela imitação.

É nesses primeiros anos da educação que o professor exerce grande influência na vida das crianças, e para tanto é preciso que o professor planeje atividades 
que tenham como objetivo estimular diversos aprendizados, levando sempre em conta o que o aluno já sabe, para que assim possa realmente contribuir com o seu aprendizado, e nenhum espaço é melhor para se descobrir o que o aluno já sabe sobre determinado assunto do que em uma roda de conversa, assim, certamente você irá suprir as necessidades de seu aluno.

Sabemos que a infância é uma das fases mais importante do desenvolvimento do indivíduo, e assim o professor nesta fase deve trabalhar o desenvolvimento com as crianças, fazendo com o que atenda os interesses $e$ as necessidades de seus alunos.

O Referencial Curricular Nacional para a Educação Infantil (RCNEI, 1998) ainda afirma que as experiências prioritárias para as crianças da educação infantil são as que envolvem a utilização da linguagem oral para se expressar, e que para isso então é preciso que o professor promova situações nas quais as crianças possam conversar, interagir verbalmente, ouvir histórias contadas e lidas pelo professor, tendo em vista que tudo isso pode ser realizado em uma roda de conversa bem planejada: outra possibilidade interessante é utilizar a gravação das rodas de conversa ou outras situações de interlocução.

Com isso, o professor pode promover novas atividades para que as crianças reformulem suas perguntas, justifiquem suas opiniões, expliquem a informação que possuem, explicitem desacordos (MEC/SEF 1998, p. 156).

Através desta prática o professor poderá também reavaliar e refletir quanto a sua prática podendo assim fazer os reajustes necessários se for o caso, pois criança em sua fala traz seus modos próprios e particulares de pensar, o que não pode ser confundido com um falar sem sentido.

Desta forma, cabe ao professor ajudar seus alunos a se expressarem, criando um clima de respeito, afeto e confiança onde as crianças possam desfrutar o prazer e a necessidade de se comunicar apoiadas na parceria do adulto, o que é fundamental, especialmente se tratando de crianças pequenas.

\section{CONSIDERAÇÕES FINAIS}

O presente artigo teve como objetivo discutir a importância da roda de conversa no desenvolvimento escolar das crianças, para que ao respeitar, interagir e descobrir de maneira prazerosa o que cada aluno já sabe, o professor possa utilizar a roda 
de conversa, pois as habilidades infantis devem começar a ser trabalhado o mais cedo possível, para que possam adquirir conhecimentos, assim auxiliando nesse processo de aprendizagem, onde vivenciam acontecimentos significativos, que irão servir de base para sua rotina diária dentro da sala de aula.

A roda de conversa disponibiliza novos aprendizados tanto para o aluno como para o professor, pois na sala de aula a conversa tem qualidades específicas, o professor deve agir buscando significados e conhecimentos da situação. Não há aluno que não pode aprender e não existe professor que saiba de tudo, segundo Freire (1996, p. 25): "[...] quem ensina aprende ao ensinar e quem aprende ensina ao aprender [...]."

A roda de conversa além de proporcionar estes momentos de aproximação entre professor e aluno, auxilia no processo de ensino e aprendizagem do grupo, pois é nesse momento e espaço, que a professora pode planejar e realizar as tarefas e rotinas diárias. E exercitar a participação ativa das crianças, incentivando-as a falarem e até serem mediadora da roda, portanto, este momento estimula a criança a perder a vergonha e ter autonomia na fala e a expressar suas idéias.

A roda é um tempo/espaço muito importante que o professor pode utilizar para mediação do conhecimento. Para ser um espaço/tempo de qualidade, a roda deve ter um planejamento, ou seja, a roda deve ser planejada pelos professores para ter uma intencionalidade. É importante também ressaltar que a roda além de proporcionar inúmeras aprendizagens para as crianças, pode ser utilizada para a construção coletiva de regras e combinados, tanto para regulamentar o momento de roda quanto para o momento das atividades diárias.

O momento da roda estimula as crianças a criar autonomia, expor suas idéias, aprender a trabalhar em grupo. Além disso, a conversa em roda também possibilita que as crianças aprendam palavras diferentes, assuntos variados, aprendam a fazer debates, enfim, esses momentos são com toda certeza muito importantes para as crianças se perceberem como seres humanos que tem muita importância na sociedade.

Assim finalizamos dizendo que é possível utilizar a roda de conversa como ferramenta pedagógica em sala de aula na Educação Infantil. 


\section{REFERÊNCIAS BIBLIOGRÁFICAS}

BRASIL. Ministério. E.D.S.E.F. Aprendizagem significativa e conhecimentos prévios. Ministério da Educação e do Desporto, Secretaria de Ed. Fundamental, 1998, vi, p.33. Disponível em < http://portal.mec.gov.br >. Acesso em 16/o7/202I.

BRASIL. Referencial curricular nacional para a educação infantil / Ministério da Educação e do Desporto, Secretaria de Educação Fundamental. Brasília: MEC/SEF, 1998.

BOMBASSARO, M. C. A Roda na Escola Infantil. Porto Alegre, 20io. Disponível em: 〈http://www.lume.ufrgs.br> Acesso em i6/o7/2021.

CHAER, Mirella Ribeiro; GUIMARÃES, Edite da Gloria Amorim. A importância da oralidade: educação infantil e séries iniciais do Ensino Fundamental. Centro Universitário de Patos de Minas. Pergaminho, (3):71-88, nov. 20I2. Disponível em <https://www.ufjf.br. Acesso em 17/o7/2021.

FREIRE, Paulo. Pedagogia da autonomia: saberes necessários à prática educativa. São Paulo: Paz e Terra, 1996. Disponível em 〈https://webcache.googleusercontent.com〉. Acesso em I7/07/2021.

FREIRE, P.; SHOR, I. Medo e ousadia. Rio de Janeiro: Paz e Terra, 1987.

JUNQUEIRA FILHO, Gabriel de Andrade. Múltiplas, diferentes e conflituosas linguagens: Um estudo sobre linguagem e organização do trabalho na educação infantil. 2005. Disponível em <http: //www.ufrgs.br. Acesso em I6/07/2021.

MOURA, Adriana F. LIMA, Maria G. A reinvenção da roda: roda de conversa, um instrumento metodológico possível. Revista Temas em Educação, João Pessoa, v.23, n.I, p. 98-ı06, jan-jun. 2014.

RONCATO, Caroline Cominetti; LACERDA, Cristina Broglia Feitosa. Possibilidades de desenvolvimento de linguagem no espaço da Educação Infantil. Revista Distúrbios da Comunicação, São Paulo, v.31, no 2, p. 215-223, ago. 2005. Disponível em 〈http://revistas.pucsp.br> Acesso em 17/o7/2021.

SILVA, Regina Broco Lima da. A Roda da conversa na educação infantil: a constituição da criança como sujeito. Americana: Centro Universitário Salesiano de São Paulo, 2016.

VYGOTSKY, L.S. A formação social da mente. São Paulo: Martins Fontes, 1994.

WARSCHAUER, Cecília. A Roda e o Registro: uma parceria entre professor, alunos e conhecimento. Rio de Janeiro: Paz e Terra, 1993. 